\title{
Publisher Correction: Revisiting energy expenditure: how to correct mouse metabolic rate for body mass
}

Timo D. Müller (D, Martin Klingenspor (D) and Matthias H. Tschöp (D)

Correction to: Nature Metabolism https://doi.org/10.1038/s42255-021-00451-2, published online 6 September 2021.

In the version of this Comment initially published, an error appeared in Fig. 1i for the significance reported in the ANCOVA analysis. Originally reading " $P>0.01$ ", the value should instead have read " $P<0.01$." The error has been corrected in the online version of the article.

Published online: 8 October 2021

https://doi.org/10.1038/s42255-021-00485-6

(C) Springer Nature Limited 2021 